\title{
The influence of selected static and dynamic parameters of resilient mats on vibration reduction of railway tracks
}

\author{
Cezary Kraśkiewicz ${ }^{1,}$, Artur Zbiciak ${ }^{1}$, Wojciech Oleksiewicz ${ }^{1}$, and Andrzej Piotrowski ${ }^{2}$ \\ ${ }^{1}$ Warsaw University of Technology, Faculty of Civil Engineering, Institute of Roads and Bridges, \\ Al. Lecha Kaczyńskiego 16, 00-637 Warsaw, Poland \\ ${ }^{2}$ Warsaw University of Technology, Faculty of Civil Engineering, Institute of Building Engineering, \\ Al. Lecha Kaczyńskiego 16, 00-637 Warsaw, Poland
}

\begin{abstract}
The paper presents laboratory methods of testing the prototype resilient mats, used in rail track systems in order to reduce vibrations transmitted to the vicinity of the railroad and to improve the resistance of the railroad structure. The laboratory testing program was carried out for elastomeric materials (polyurethane based). The key parameters being investigated in the Warsaw University of Technology laboratory unit were used in order to determine the insertion loss vibration level by applying analytical method. The paper presents the influence of selected parameters i.e. static and dynamic moduli on the reduction of vibration and structureborne sound level - i.e. the value of insertion loss parameters.
\end{abstract}

\section{Introduction}

Resilient mats can be grouped into two categories, because of the range of applications in various types of railways track construction:

a) Under-Ballast Mats (UBM)/Sub-Ballast Mats (SBM) - used in ballast railway track; among which two varieties can be classified due to the main purpose of their use according to standard [1]:

- used primarily for isolation from vibration $[2,3]$,

- used primarily for stress reduction in ballast $[4,5]$.

b) Slab-Track Mats (STM) - used in ballastless railway track (applied under or from the sides of concrete track base plate, including three varieties of slab support system according to standard [6]:

- discrete support (steel springs or elastomeric pads),

- linear support (strip mats),

- continuous support (elastomeric mats).

\footnotetext{
*Corresponding author: c.kraskiewicz@,il.pw.edu.pl
} 


\section{Parameters characterizing static and dynamic properties of resilient mats}

As there are no European standards to define the requirements and methodology of research for resilient mats in railway tracks, it is justifiable to use German Standards: DIN 45673-1 [7], DIN 45673-5 [1] and DIN 45673-7 [6]. All the substantial characteristics of resilient mats and procedures for their research are presented in study [8].

Static and dynamic bedding moduli determine effectiveness of dumping vibrations transmission to the environment. It should be noted that the mats possessing very low value of static bedding modulus give in greater vertical deflection of rail and railway track. The value of the static and dynamic bedding modulus is defined for resilient mats for linear and continuous support. It includes a wide range of values from $\sim 0.003$ to $\sim 0.33 \mathrm{~N} / \mathrm{mm}^{3}$, depending on the material type and structure, thickness of the mat, the load value in which bedding modulus is defined and the load frequency for dynamic modulus.

\subsection{Laboratory tests}

In the research laboratory unit at the Warsaw University of Technology (Fig. 1), UBM mats were tested in accordance with the requirements of the DIN 45673-5 [1] Standard and STM mats in accordance with DIN 45673-7 [6]. The polyurethane-based mats with a thickness of $15 \mathrm{~mm}$ and of diversified densities were tested: G180 $\left(180 \mathrm{~kg} / \mathrm{m}^{3}\right), \mathrm{G} 160\left(160 \mathrm{~kg} / \mathrm{m}^{3}\right)$ and G150 $\left(150 \mathrm{~kg} / \mathrm{m}^{3}\right)$. Dimensions of test samples: $300 \mathrm{~mm} \times 300 \mathrm{~mm}$. Test temperature: $(23 \pm 3)^{\circ} \mathrm{C}$. The method of load application: flat loading plate - UBM/STM - flat loading plate (Fig. 1). The loading plate is made of steel with a sanding disc (K120 grit on a rigid linen backing cloth) inserted between the loading plate and the test object. The sample loading was applied by the INSTRON 8802 machine and the deflections were measured by four displacement sensors.

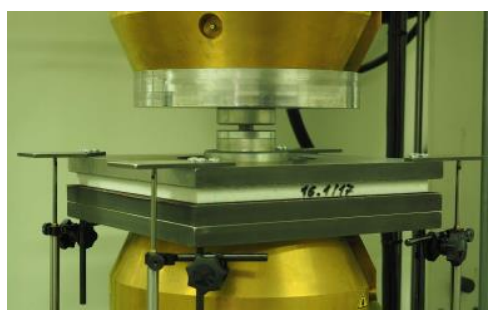

Fig. 1. View of tested sample STM G150.

\subsection{Static bedding modulus}

Static bedding modulus characterizes conditions of rail deflection under the pressure of non-moving rolling stock. It also affects the vertical deflection of railway track in floating slab track system. The relationship between static bedding modulus and the applied force is non-linear. In such cases, the static bedding modulus is determined within different ranges of loads, depending on the application purpose of resilient mat. Based on displacements $s_{1}$ and $s_{2}$ the static bedding modulus can be evaluated in $\mathrm{N} / \mathrm{mm}^{3}$ as a secant modulus with respect to the range of stresses to be assessed $\sigma_{1}$ and $\sigma_{2}$ as expressed via Eq. (1).

$$
C_{\text {stat }}=\frac{\sigma_{2}-\sigma_{1}}{s_{2}-s_{1}} \quad\left[\mathrm{~N} / \mathrm{mm}^{3}\right]
$$


Static bedding modulus diagrams are shown in Fig. 2 and its numerical values within different evaluation ranges of loads in Tab. 1.

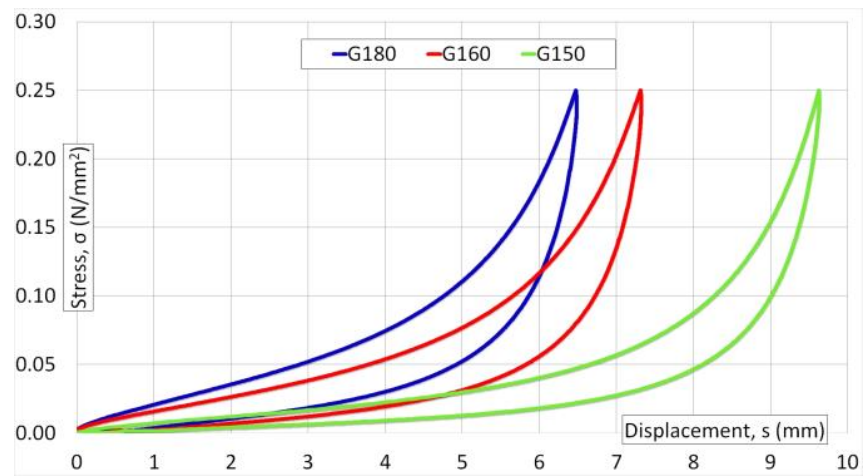

Fig. 2. Static bedding modulus of STM G180/160/150 according to DIN 45673-5 [1].

Table 1. Static bedding modulus of resilient mats.

\begin{tabular}{|c|c|c|c|}
\hline $\begin{array}{c}\text { Evaluation } \\
\text { range of loads } \\
{\left[\mathrm{N} / \mathrm{mm}^{2}\right]}\end{array}$ & \multicolumn{3}{|c|}{ Static bedding modulus $C_{\text {stat }}\left[\mathrm{N} / \mathrm{mm}^{3}\right]$} \\
\cline { 2 - 4 } & $\mathrm{G} 180$ & $\mathrm{G} 160$ & $\mathrm{G} 150$ \\
\hline $0.02-0.05$ & 0.016 & 0.013 & 0.010 \\
\hline $0.02-0.07$ & 0.017 & 0.015 & 0.013 \\
\hline $0.02-0.10$ & 0.021 & 0.019 & 0.017 \\
\hline $0.02-0.20$ & 0.035 & 0.032 & 0.031 \\
\hline
\end{tabular}

\subsection{Dynamic bedding modulus and dynamic stiffening ratio}

Dynamic bedding modulus characterizes mat work under the pressure of moving rolling stock, therefore, it determines the limitation of vibration transmission. The value of dynamic bedding modulus is related not only to loading force, as in static bedding modulus, but also to frequencies. Therefore, it should be determined under the standard pressure and frequency ranges.

The DIN 45673-5 Standard [1] divided a test procedure into two groups. The first one is applied for dynamic bedding modulus within lower frequencies $C_{d y n 1}(f)(5,10,20$ and $30 \mathrm{~Hz})$, the second one within higher frequencies $C_{d y n 2}(f)(10-160 \mathrm{~Hz})$. The parameter $C_{d y n 1}(f)$ can be used to determine the lower-frequency bending deformation of the rail under the influence of the rolling wheel, as a result of the interplay of the bending elasticity of railway track structure. The parameter $C_{d y n 2}(f)$ refers to under-ballast mats and can be used to determine the level of reduction of structure-borne noise. It influences the natural frequency $f_{0}$ of the elastically supported track as an oscillatory system and thus the insertion loss.

Dynamic stiffening ratio $r(f)$ is a proportion between dynamic and static bedding modulus - Eq. (2). It defines the possibility of achieving effective vibration damping for resilient mats. Because of the known property of elastomeric materials being ratedependent, both bedding modulus as well as stiffness modulus are determined for various frequencies of excitation. The closer to 1 the value of dynamic stiffening ratio is (for $r(f)>1$ ), the better vibration isolation properties has the test piece (e.g. resilient mat). 


$$
r(f)=\frac{C_{d y n(f)}}{C_{\text {stat }}}
$$

Dynamic bedding modulus $(5 \mathrm{~Hz})$ diagrams for UBM are shown in Fig. 3 and numerical values of dynamic bedding modulus/dynamic stiffening ratio for evaluation range of loads $0.02-0.07 \mathrm{~N} / \mathrm{mm}^{2}$ according to DIN 45673-5 [1] in Tab. 2 .

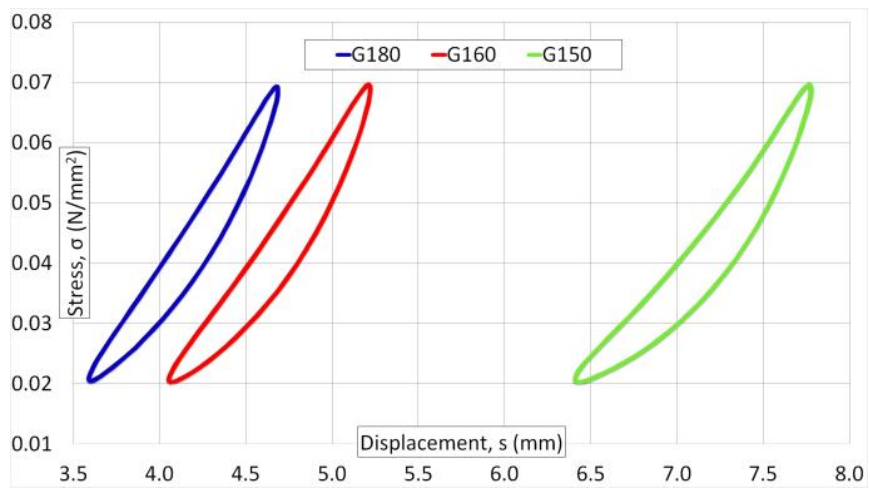

Fig. 3. Dynamic bedding modulus (5 Hz) of UBM G180/160/150 according to DIN 45673-5 [1].

Table 2. Dynamic bedding modulus/dynamic stiffening ratio of resilient mats UBM for evaluation range of loads $0.02-0.07 \mathrm{~N} / \mathrm{mm}^{2}$ according to DIN 45673-5 [1].

\begin{tabular}{|c|c|c|c|}
\hline Parameter & G180 & G160 & G150 \\
\hline dynamic bedding modulus $C_{d y n 1}(5 \mathrm{~Hz})\left[\mathrm{N} / \mathrm{mm}^{3}\right]$ & 0.046 & 0.043 & 0.037 \\
\hline dynamic stiffening ratio $r(5 \mathrm{~Hz})[1]$ & 2.68 & 2.85 & 2.84 \\
\hline dynamic bedding modulus $C_{d y n 1}(10 \mathrm{~Hz})\left[\mathrm{N} / \mathrm{mm}^{3}\right]$ & 0.059 & 0.049 & 0.041 \\
\hline dynamic stiffening ratio $r(10 \mathrm{~Hz})[1]$ & 2.92 & 3.28 & 3.15 \\
\hline
\end{tabular}

Dynamic bedding modulus $(20 \mathrm{~Hz})$ diagrams for STM are shown in Fig. 4 and numerical values of dynamic bedding modulus/dynamic stiffening ratio mats STM for harmonic excitation with a particle velocity amplitude of $7 \mathrm{~mm} / \mathrm{s}$ (corresponding to a particle velocity level $L_{\mathrm{v}}=100 \mathrm{~dB}$ relative to the standard reference particle velocity of $5 \times 10^{-8} \mathrm{~m} / \mathrm{s}$ ) and preloading $S_{\mathrm{v}}=0.04 \mathrm{~N} / \mathrm{mm}^{2}$ according to DIN 45673-7 [6] in Tab. 3 .

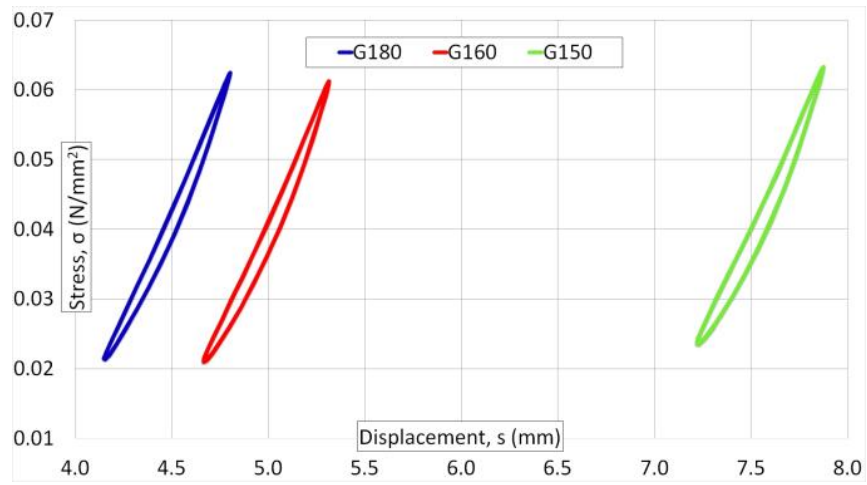

Fig. 4. Dynamic bedding modulus (20 Hz) of STM G180/160/150 according to DIN 45673-7 [6]. 
Table 3. Dynamic bedding modulus /dynamic stiffening ratio of resilient mats STM for harmonic excitation with a particle velocity amplitude of $7 \mathrm{~mm} / \mathrm{s}$ and preloading $S_{\mathrm{v}}=0.04 \mathrm{~N} / \mathrm{mm}^{2}$ according to DIN 45673-7 [6].

\begin{tabular}{|c|c|c|c|}
\hline Parameter & G180 & G160 & G150 \\
\hline dynamic bedding modulus $C_{d y n 1}(5 \mathrm{~Hz})\left[\mathrm{N} / \mathrm{mm}^{3}\right]$ & 0.028 & 0.028 & 0.030 \\
\hline dynamic stiffening ratio $r(5 \mathrm{~Hz})[1]$ & 1.63 & 1.86 & 2.34 \\
\hline dynamic bedding modulus $C_{d y n 1}(10 \mathrm{~Hz})\left[\mathrm{N} / \mathrm{mm}^{3}\right]$ & 0.039 & 0.039 & 0.039 \\
\hline dynamic stiffening ratio $r(10 \mathrm{~Hz})[1]$ & 2.29 & 2.58 & 2.97 \\
\hline dynamic bedding modulus $C_{d y n 1}(20 \mathrm{~Hz})\left[\mathrm{N} / \mathrm{mm}^{3}\right]$ & 0.058 & 0.057 & 0.056 \\
\hline dynamic stiffening ratio $r(20 \mathrm{~Hz})[1]$ & 3.40 & 3.78 & 4.31 \\
\hline
\end{tabular}

\section{Mechanical model of ballast railway track}

Discrete mechanical model of the ballast railway track is shown in Fig. 5. Such a model was partially analysed in [9] and is also presented in Standard [10] for calculation of insertion loss. The state-space formulation of differential equations representing this model was given in [11] taking into account the algorithm of eigenvalue problem solution described in [12]. In this section we demonstrate dynamic behaviour of the system retrofitted with viscoelastic fractional model of Under-Ballast Mats (UBM) (Fig. 5b). Selected features of the system with UBM will be visualized comparing the reference system without UBM (see Fig. 5a).

The reference system is composed of two layers. The parameters $k_{\mathrm{o}}=220 \mathrm{MN} / \mathrm{m}$ and $d_{\mathrm{o}}=0.265 \mathrm{MNs} / \mathrm{m}$ represent stiffness and damping of upper layer of the system (rail, fastening, sleeper and ballast) while $k_{u}=1500 \mathrm{MN} / \mathrm{m}$ and $d_{u}=1.2 \mathrm{MNs} / \mathrm{m}$ define lower layer (track-bed). Effective mass of both reference as well as retrofitted (isolated) systems are $m_{e f f}=2600 \mathrm{~kg}$.

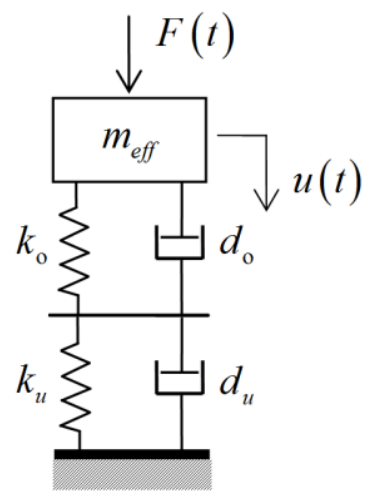

(a)

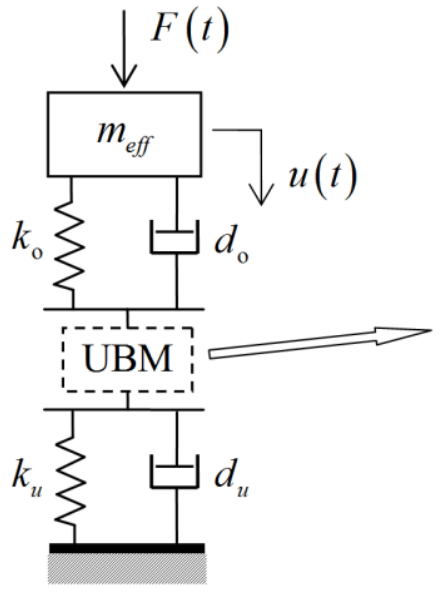

(b)

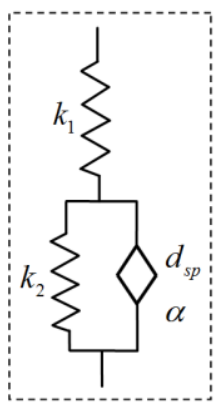

(c)

Fig. 5. Reference model of ballast railway track (a), system with UBM (b) and rheological model of $\operatorname{UBM}(\mathrm{c})$. 
In the case of an isolated system, an additional layer is considered representing UnderBallast Mat. Rheological viscoelastic model of UBM is shown in Fig. 5c. The model is composed of two springs $k_{1}$ and $k_{2}$ and of a fractional element (spring-pot) defined by two parameters $d_{s p}$ and $\alpha$. Constitutive relationships of the spring-pot element, relating the force $f(t)$ and the displacement $u_{s p}(t)$, can be expressed in a differential form (see [13])

$$
f(t):=d_{s p} \mathrm{D}^{\alpha} u_{s p}(t) ; \quad \alpha \in(0,1)
$$

where $\mathrm{D}^{\alpha} \equiv \frac{\mathrm{d}^{\alpha}}{\mathrm{d} t^{\alpha}}$ denotes fractional derivative operator:

$$
\begin{gathered}
\mathrm{D}^{\alpha} u_{s p}(t):=\frac{u_{s p}(0)}{\Gamma(1-\alpha) t^{\alpha}}+\frac{1}{\Gamma(1-\alpha)} \int_{0}^{t} \frac{\dot{u}_{s p}(\tau)}{(t-\tau)^{\alpha}} \mathrm{d} \tau \\
\Gamma(1-\alpha):=\int_{0}^{\infty} t^{-\alpha} e^{-t} \mathrm{~d} t
\end{gathered}
$$

The complex stiffness of the UBM model $k_{U B M}^{*}$ and of entire isolated system $k_{v i b}^{*}$ can be defined as follows $[14,15]$

$$
\begin{aligned}
& k_{U B M}^{*}(i \omega)=\left(\frac{1}{k_{1}}+\frac{1}{k_{2}+d_{s p}(i \omega)^{\alpha}}\right)^{-1} \\
& k_{v i b}^{*}(i \omega)=\left[\frac{1}{k_{r e f}^{*}(i \omega)}+\frac{1}{k_{U B M}^{*}(i \omega)}\right]^{-1}
\end{aligned}
$$

Another formulas defining complex transfer functions, insertion loss and complex compliance moduli were presented in [9].

Based on laboratory results presented in previous section, rheological parameters of three types of UBM were evaluated. The results of a curve fitting procedure are presented in Table 4 and depicted in Fig. 6. The curve fitting procedure is based on evaluation of dynamic stiffness moduli being the absolute value of the complex stiffness $k_{U B M}^{*}$.

Table 4. Curve fitting results of rheological models of UBMs.

\begin{tabular}{|c|c|c|c|c|}
\hline $\mathrm{UBM}$ & $k_{1}[\mathrm{MN} / \mathrm{m}]$ & $k_{2}[\mathrm{MN} / \mathrm{m}]$ & $d_{s p}\left[\mathrm{MNs}^{\alpha} / \mathrm{m}\right]$ & $\alpha[-]$ \\
\hline $\mathrm{G} 180$ & 6.079 & 2.016 & 0.234 & 0.891 \\
\hline $\mathrm{G} 160$ & 4.764 & 1.850 & 0.259 & 0.898 \\
\hline $\mathrm{G} 150$ & 3.866 & 1.674 & 0.275 & 0.899 \\
\hline
\end{tabular}

It should be emphasized that the values of bedding moduli evaluated based on the curve fitting procedure (Fig. 6) were divided by the area of the sample $(300 \times 300 \mathrm{~mm})$ in order to obtain stiffness moduli shown in Table 4 (see [8]). 


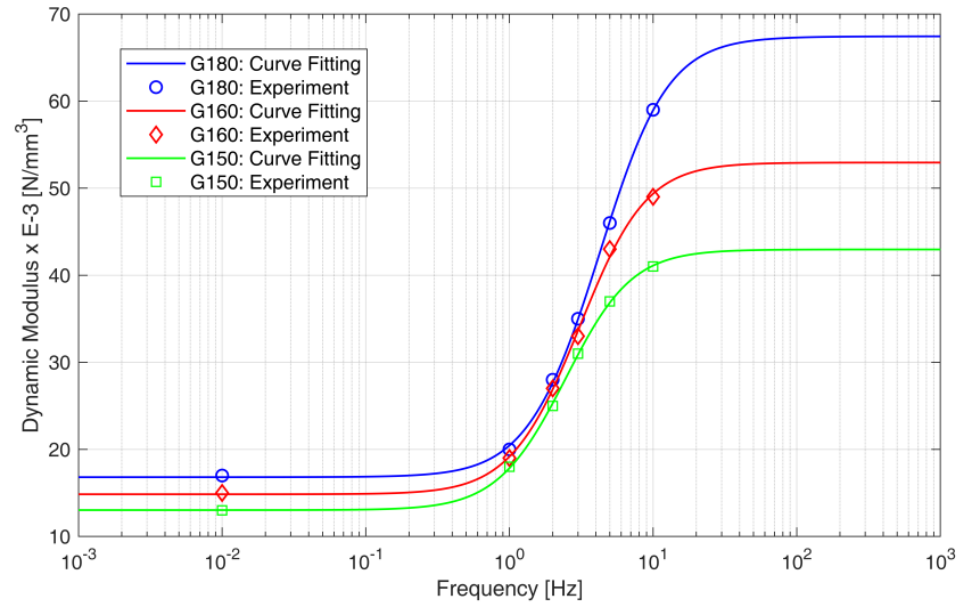

Fig. 6. Curve fitting results for three analysed UBM models.

The calculation results for both reference system and vibro-isolated system with UBM G180 are visualized in Fig. 7. Horizontal axis used in Fig. 7 represents centre frequencies of $1 / 3$ octave bands. The plots depicted in Fig. 7 indicate a region of vibration-isolation effectiveness for approx. freq $>9.5 \mathrm{~Hz}$ where $I L>0 \mathrm{~dB}$ (see vertical dashed line). It was proved that in case of G160, the verge of vibration-isolation effectiveness equals $8.8 \mathrm{~Hz}$ while for G150 it starts from $8.1 \mathrm{~Hz}$.

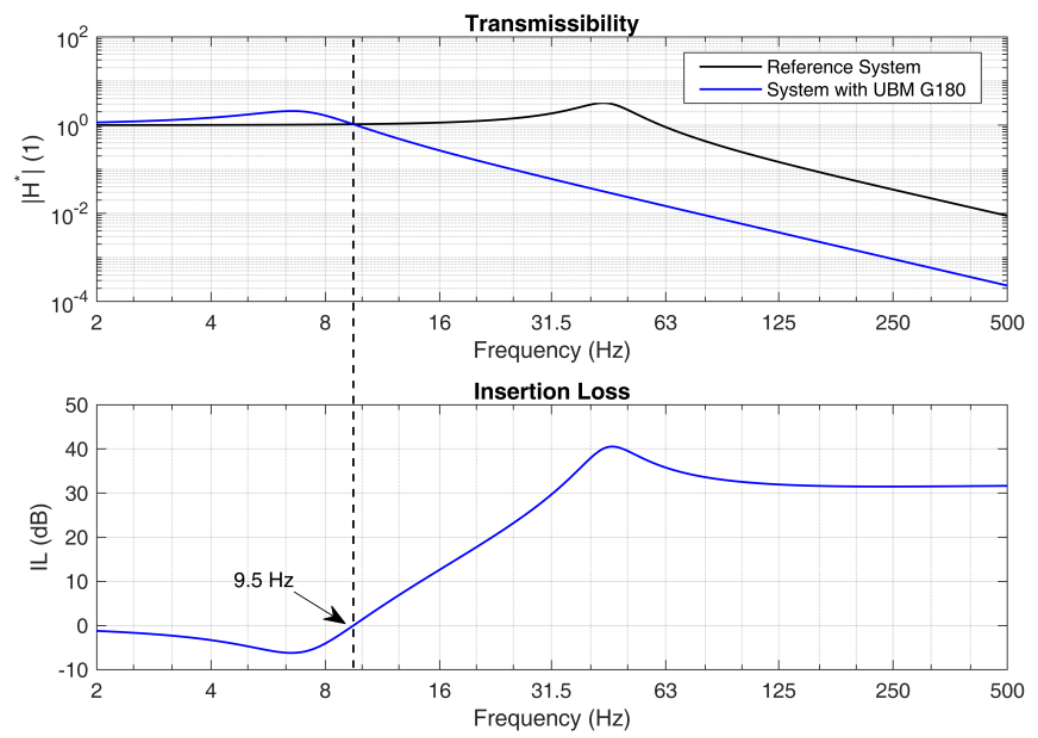

Fig. 7. Transmissibility and Insertion Loss: reference system and system with Under-Ballast Mat (UBM G180).

Such diagrams are presented in numerous papers $[16,17,18]$ for various mechanical models representing railway track systems with vibroacoustic isolators.

In further studies, the results of vibration reduction forecasts will be compared with the results of measurements performed on test sites in accordance with the requirements of the standards $[19,20]$. 


\section{Conclusions}

The key parameters (static bedding modulus, dynamic bedding modulus and dynamic stiffening ratio) being investigated at the Warsaw University of Technology laboratory unit were used in order to determine the insertion loss vibration level by applying analytical method. The paper confirmed the influence of selected parameters i.e. static and dynamic bedding moduli on the reduction of vibration and structure-borne sound level - i.e. the value of insertion loss parameters.

\section{References}

1. DIN 45673-5:2010-08 Mechanical vibration. Resilient elements used in railway tracks. Part 5: Laboratory test procedures for under-ballast mats

2. M. Butorina, N. Minina, P. Ivanov, A. Petryaev, Procedia Engineering 189, 352-359 (2017)

3. P.Carels, Joint Baltic-Nordic Acoustic Meeting 2012, 1-16 (2012)

4. S. K. Navaratnarajah, B. Indraratna, Journal of Geotechnical and Geoenvironmental Engineering, 143, 6 (2017)

5. S. K. Navaratnarajah, B. Indraratna, S. Nimbalkar, Procedia Engineering 143, $1108-$ 1119 (2016)

6. DIN 45673-7:2010-08 Mechanical vibration - Resilient elements used in railway tracks - Part 7: Laboratory test procedures for resilient elements of floating slab track systems

7. DIN 45673-1:2010-08 Mechanical vibration. Resilient elements used in railway tracks. Part 1: Terms and definitions, classification, test procedures

8. C. Kraśkiewicz, C. Lipko, M. Płudowska, W. Oleksiewicz, A. Zbiciak, Procedia Engineering 153, 317-324 (2016)

9. A. Zbiciak, C. Kraśkiewicz, C. Lipko, W. Oleksiewicz, IPICSE-2016, MATEC Web of Conferences 86, 01015 (2016)

10. DIN 45673-4:2008-07 Mechanical vibration. Resilient elements used in railway tracks. Part 4: Analytical evaluation of insertion loss of mounted track systems

11. A. Zbiciak, C. Kraśkiewicz, W. Oleksiewicz, M. Płudowska-Zagrajek, C. Lipko, XXVI $R$-S-P Seminar 2017, TFoCE, MATEC Web of Conferences 117, 00090 (2017)

12. V. G. S. Simionatto, H. H. Miyasato, F. Melo, M. Junior, Proceedings $21^{\text {st }}$ Int. Congr. Mech. Engin. (2011)

13. W. Grzesikiewicz, A. Wakulicz, A. Zbiciak, IJMS 70, 90-98 (2013)

14. R. W. Clough, J. Penzien, Dynamics of Structures (McGraw-Hill, 1975)

15. J. Sołkowski, Proceeding, Research and Technical Papers of Polish Association for Transportation Engineers in Cracow 2(106), 159-175 (2015)

16. R. G. Wettschureck, U. J. Kurze, ACUSTICA 58, 177-182 (1985)

17. R. G. Wettschureck, DAGA 87, 217-220 (1987)

18. R. G. Wettschureck, M. Heim, S. Mühlbachler, Proceedings Inter-noise 97, 577-580 (1997)

19. DIN 45672-1:2018-02 Vibration measurement associated with railway traffic systems Part 1: Measuring method for vibration

20. DIN 45672-2:1995-07 Vibration measurement associated with railway traffic systems Part 2: Evaluation method 